\title{
Effects of feeding a fermented product on egg production, faecal microflora and faecal $\mathrm{pH}$ in laying hens
}

\author{
T.C. Loh", ${ }^{1,5}$ F.L. Law ${ }^{1}$, H.L. Foo ${ }^{3,4}$, Y.M. Goh ${ }^{3}$ and I. Zulkifli ${ }^{1}$ \\ University Putra Malaysia, \\ ${ }^{1}$ Department of Animal Science, \\ ${ }^{2}$ Department of Bioprocess Technology, \\ ${ }^{3}$ Department of Veterinary Preclinical Sciences, \\ ${ }^{4}$ Institute of Bioscience \\ 43300 Serdang, Selangor, Malaysia
}

(Received 2 February 2007; revised version 12 July 2007; accepted 6 September 2007)

\begin{abstract}
This study was conducted to investigate the effects of feeding fermented product (FP) to layers on laying performance, faecal microflora and $\mathrm{pH}$. A total of 96, 13-week-old Babcock B380 pullets were used in the study. They were randomly assigned to four numerically equal groups with eight replicates per treatment, three birds per replicate. All the birds were caged individually. The treatments consisted of Diet 1 (Control), without FP, Diet 2 (FP3) contained 3\% (w/w) FP (30g FP/kg diet), Diet 3 (FP6) contained 6\% (w/w) FP (60 g FP/kg diet) and Diet 4 (FP9) contained 9\% (w/w) FP (90 g FP/kg diet). The study was conducted for 14 weeks with 2 weeks of acclimatization. Fresh faecal samples were collected fortnightly started from 15 weeks of age. The feed intake, egg production, feed conversion ratio (feed intake, g/egg mass, g), egg mass (egg x egg production/100) and egg weight were not affected by the addition of FP at any level in the diets. However, the egg weight for FP6 was significantly higher than FP9. The faeces samples were cultured for lactic acid bacteria (LAB) and Enterobacteriaceae. The results obtained from this study showed that FP reduced $(\mathrm{P}<0.05)$ the faecal Enterobacteriaceae and $\mathrm{pH}$ value. Higher $(\mathrm{P}<0.05)$ counts of faecal LAB in layers fed with FP were observed. In conclusions, these results indicate that FP could be included up to $6 \%$ in the diets of layers contributed to heavier egg weight and shifting the microflora composition of the layers' gastrointestinal tract toward a beneficial balance.
\end{abstract}

KEY WORDS: fermented product, layer, egg, lactic acid bacteria, Enterobacteriaceae

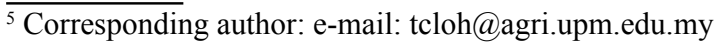




\section{INTRODUCTION}

Utilization of feed additive is a common practice to improve the productivity of animals. Addition of antibiotic growth promoter is the most common approach. However, the extensive use of antibiotics as growth enhancer may lead to the development of antimicrobial resistance against pathogenic bacteria species (Mikkelsen and Jensen, 2000). This may hamper the effectiveness of treatment in infected humans especially in the event of human-animal infections. Furthermore, the EU countries have already imposed ban on the use of antibiotic in the dietary of animals as growth enhancer. Recently, fermented feed was suggested as alternatives to the antibiotic growth promotants (Mikkelsen and Jensen, 2000; Demecková et al., 2002; van Winsen et al., 2002; Loh et al., 2003a,b). Therefore, it has become an important and rapidly expanding segment of the animal feed market. This is one of the avenues to minimize or even eliminate the need for antibiotics in feeds. Feeding fermented liquid and fermented fruits to animals resulted in the reduction of coliform numbers in the digestive tract (Mikkelsen and Jensen, 2000; van Winsen et al., 2001, 2002; Demecková et al., 2002; Canibe and Jensen, 2003; Højberg et al., 2003; Loh et al., 2003a,b; Heres et al., 2004). In addition, feeding fermented feed results in the increase of feed intake post-weaning and thus increase post-weaning growth rate in piglets (Mikkelsen and Jensen, 2000). It also has been reported that feeding fermented solid product (Loh et al., 2003a,b) has a similar effect as feeding fermented liquid feed (Mikkelsen and Jensen, 2000; Demecková et al., 2002; van Winsen et al., 2002; Canibe and Jensen, 2003; Højberg et al., 2003; Heres et al., 2004). However, there is no information on the effects of feeding fermented solid products to layers on their laying performance, faecal microflora counts and $\mathrm{pH}$ in faeces. Thus, the objectives of this experiment were to study the effects of different levels of FP inclusions in the diets of layers on the laying performance, population of faecal microflora and its $\mathrm{pH}$.

\section{MATERIAL AND METHODS}

\section{Experimental birds and diets}

This experiment was carried out on 96 13-week old Babcock B380 pullets with an average body weight of $1.19 \mathrm{~kg} \pm 0.01(\mathrm{BW} \pm \mathrm{SE})$. All the birds were kept individually in wire cages $(36 \times 30 \times 35 \mathrm{~cm})$ in an open layer house. They were randomly allotted to four dietary treatments, with eight replicates per treatment, three birds per replicate. The dietary treatments comprised of basal diet without the FP as control, and experimental diets containing 3\% FP (w/w) (FP3), (w/w) (FP6) and 9\% (w/w) (FP9). The contents of the FP used in this study consisted of, \%: 
$(\mathrm{w} / \mathrm{w})$ lime $9,(\mathrm{v} / \mathrm{w})$ molasses 1, (w/w) rice bran 53.5, (w/w) fish (Rastrelliger kanagurta) $35,(\mathrm{v} / \mathrm{w})$ vinegar 1 and $(\mathrm{w} / \mathrm{w})$ starter cultures 0.5 . The starter cultures comprised of Lactobacillus plantarum isolated from 'tempeh', a local fermented food as described by Foo et al. (2003). The fermentation process was conducted according Loh et al. (2003a,b). The experimental feeds were provided in mash form. The diet compositions of pullet and layer are shown in Tables 1 and 2, respectively. The diets were formulated as isonitrogenous and isoenergetic. The dry matters of the pullet and layer diets were ranged from 88.20 to $88.36 \%$ and the Enterobacteriaceae count was $0.83 \pm 0.16\left(\log _{10}\right.$ $\mathrm{cfu} / \mathrm{g})$. The birds were adapted to the respective diets for 2 weeks and the experimental period was conducted for another 14 weeks. Individual body weight was measured at the beginning and end of the experiment. Water and feed were supplied ad libitum. The birds were raised under natural light circumstances. The feed was offered early in the morning (08.00) and in the evening (17.00). Feed intake was measured weekly for each treatment groups. Feed conversion ratio (FCR) was then calculated based on the formula: $\mathrm{FCR}=$ feed intake (g)/egg mass (g).

Table 1. Compositions of pullet diets, from 13-18 weeks of age

\begin{tabular}{lrrrr}
\hline Item & Control & FP3 & FP6 & FP9 \\
\hline Ingredients, \% & & & & \\
maize & 60.15 & 58.65 & 56.81 & 54.97 \\
palm oil & 2.50 & 2.20 & 1.94 & 1.70 \\
soyabean meal (44\%) & 31.30 & 30.10 & 29.20 & 28.28 \\
L-lysine & 0.20 & 0.20 & 0.20 & 0.20 \\
DL-methionine & 0.20 & 0.20 & 0.20 & 0.20 \\
MDCP & 3.00 & 3.00 & 3.00 & 3.00 \\
limestone & 1.10 & 1.10 & 1.10 & 1.10 \\
salt & 0.40 & 0.40 & 0.40 & 0.40 \\
vitamin premix & 0.08 & 0.08 & 0.08 & 0.08 \\
mineral premix & 0.07 & 0.07 & 0.07 & 0.07 \\
choline chloride & 1.00 & 1.00 & 1.00 & 1.00 \\
FP & - & 3.00 & 6.00 & 9.00 \\
& & & & \\
Calculated values & & & & 12.23 \\
ME, MJ/kg & 12.23 & 12.23 & 12.23 & 18.86 \\
crude protein, \% & 18.89 & 18.81 & 18.84 & 0.98 \\
lysine, \% & 0.98 & 0.98 & 0.98 & 0.44 \\
methionine, \% & 0.42 & 0.43 & 0.43 & . \\
\hline
\end{tabular}

${ }^{1}$ the vitamin-premix per kg of diet, IU: vit. A 50.0, vit. $\mathrm{D}_{3} 8.0$, g: vit. E 200, vit. $\mathrm{B}_{2} 20.0$, vit. $\mathrm{B}_{6} 20.0$, vit. $\mathrm{B}_{12} 1.0$, vit. $\mathrm{K}_{3} 10.0$, biotin 0.8 , panthothenic acid 80.0 , folic acid 10.0 , niacin 130.0 , anticaking agent 20.0 and antioxidant 0.2

${ }^{2}$ the mineral premix provides the following amounts per $\mathrm{kg}$ of diet, g: Mn 20.0, Fe 80.0, Zn 80.0, $\mathrm{Cu} 10.0$, Co 0.2 , I 0.3 and Se 0.3

FP - fermented product 
Table 2. Compositions of layer diets, from 19 weeks to 29 weeks of age

\begin{tabular}{lrrrr}
\hline Item & Control & FP3 & FP6 & FP9 \\
\hline Ingredient, \% & & & & \\
maize & 60.60 & 58.55 & 57.00 & 54.30 \\
palm oil & 1.55 & 1.35 & 1.05 & 0.97 \\
soyabean meal (44\%) & 25.50 & 24.75 & 23.60 & 23.38 \\
L-lysine & 0.06 & 0.06 & 0.06 & 0.06 \\
DL-methionine & 0.16 & 0.16 & 0.16 & 0.16 \\
MDCP & 2.50 & 2.50 & 2.50 & 2.50 \\
limestone & 8.00 & 8.00 & 8.00 & 8.00 \\
salt & 0.50 & 0.50 & 0.50 & 0.50 \\
vitamin premix ${ }^{1}$ & 0.07 & 0.07 & 0.07 & 0.07 \\
mineral premix & 0.06 & 0.06 & 0.06 & 0.06 \\
choline chloride & 1.00 & 1.00 & 1.00 & 1.00 \\
FP & - & 3.00 & 6.00 & 9.00 \\
& & & & \\
Calculated values & & & & \\
ME, MJ/kg & 11.42 & 11.42 & 11.41 & 11.41 \\
crude protein, \% & 16.22 & 16.29 & 16.23 & 16.49 \\
lysine, \% & 0.88 & 0.89 & 0.89 & 0.90 \\
methionine, \% & 0.42 & 0.43 & 0.43 & 0.44 \\
\hline
\end{tabular}

${ }^{1}$ the vitamin-premix per kg of diet, IU: vit. A 50.0, vit. $\mathrm{D}_{3} 8.0$, g: vit. E 200, vit. $\mathrm{B}_{2} 20.0$, vit. $\mathrm{B}_{6} 20.0$, vit. $\mathrm{B}_{12} 1.0$, vit. $\mathrm{K}_{3} 10.0$, biotin 0.8 , panthothenic acid 80.0 , folic acid 10.0, niacin 130.0, anticaking agent 20.0 and antioxidant 0.2

${ }^{2}$ the mineral premix provides the following amounts per kg of diet, g: Mn 20.0, Fe 80.0, Zn 80.0, $\mathrm{Cu} 10.0$, Co 0.2 , I 0.3 and Se 0.3

FP - fermented product

\section{Samples collection and microflora counts}

During the laying period (from 21 to 29 weeks of age), the eggs were collected daily. The number of egg produced including the normal and abnormal eggs from all the treatments was recorded and only normal eggs were weighed. Egg mass was calculated based on the formula: egg mass $=($ egg weight $\times$ egg production $) / 100$.

A total of $3 \mathrm{~g}$ of faecal samples were collected from each replicate of each experimental group at 15, 17, 19, 21, 23, 25, 27 and 29 weeks of age during the experimental period. Fresh faecal samples were collected immediately after defecation. The samples were then placed in different sterile universal bottles in order to determine the faecal $\mathrm{pH}$, numbers of LAB and Enterobacteriaceae. The $\mathrm{pH}$ of the faeces was directly measured with a $\mathrm{pH}$ meter. The faecal $(10 \% \mathrm{w} / \mathrm{v})$ was suspended in sterile peptone water and incubated for an $\mathrm{h}$ before further 10 -fold dilutions $(\mathrm{v} / \mathrm{v})$ were made with peptone water for total LAB and Enterobacteriaceae counts. Total LAB counts were spread plated on MRS-agar (Merck ${ }^{\circledR}$ ) and incubated at $30^{\circ} \mathrm{C}$ for $48 \mathrm{~h}$, whereas Enterobacteriaceae were plated on EMB-agar (Merck ${ }^{\circledR}$ ) and incubated at $37^{\circ} \mathrm{C}$ for $24 \mathrm{~h}$ as described by 
Loh et al. (2003a,b). Numbers of colony forming units (CFU) are expressed as $\log _{10}$ CFU per $g$.

\section{Statistical analysis}

The data were analysed using the one-way analysis of variance (ANOVA) in accordance to a completely randomised design model (SAS $\left.{ }^{\circledR}, 1991\right)$. Significant differences between treatments means were compared using the Duncan's multiple range test at $\mathrm{P}<0.05$.

\section{RESULTS}

The effect of feeding fermented product (FP) on growth and laying performance in layers from 15 to 29 weeks of age is presented in Table 3. No significant difference $(\mathrm{P}>0.05)$ results were found for initial and final body

Table 3. Effects of feeding fermented product on growth and laying performance in layers from 15 to 29 weeks of age

\begin{tabular}{|c|c|c|c|c|c|}
\hline \multirow{2}{*}{ Item } & \multicolumn{4}{|c|}{ Treatments } & \multirow{2}{*}{$\begin{array}{l}\text { Signi- } \\
\text { ficance }\end{array}$} \\
\hline & control & FP3 & FP6 & FP9 & \\
\hline Initial body weight, $\mathrm{kg} / \mathrm{bird}$ & $1.20 \pm 0.01$ & $1.19 \pm 0.01$ & $1.19 \pm 0.01$ & $1.17 \pm 0.01$ & ns \\
\hline Final body weight, kg/bird & $1.67 \pm 0.02$ & $1.66 \pm 0.02$ & $1.68 \pm 0.02$ & $1.64 \pm 0.02$ & ns \\
\hline $\begin{array}{l}\text { Average daily feed intake, } \\
\text { g/day/bird }\end{array}$ & $91.03 \pm 1.82$ & $92.64 \pm 1.02$ & $89.25 \pm 1.32$ & $91.26 \pm 1.07$ & ns \\
\hline $\begin{array}{l}\text { Average egg production, } \\
\text { at } 29 \text { weeks of age, } \%\end{array}$ & $85.71 \pm 4.38$ & $88.69 \pm 2.58$ & $82.14 \pm 3.36$ & $91.07 \pm 2.24$ & ns \\
\hline $\begin{array}{l}\text { Average feed conversion ratio, } \\
\mathrm{g} \text { feed intake/g egg mass }\end{array}$ & $1.96 \pm 0.07$ & $2.05 \pm 0.09$ & $2.10 \pm 0.06$ & $2.10 \pm 0.07$ & ns \\
\hline
\end{tabular}

the results are presented as mean values $\pm \mathrm{SE}$

values with different superscripts within rows differ significantly at $\mathrm{P}<0.05$

${ }^{\text {ns }}$ no significant difference

* $\mathrm{P}<0.05$

weights, average daily fed intake, egg production and FCR between the treatment groups. Figure 1 shows the effects of feeding FP on egg mass of layers. There was no significant difference $(\mathrm{P}>0.05)$ in egg mass among the treatment groups throughout the experimental period. However, the egg produced by hens fed with FP had slightly lower mass as compare with the control hens during the laying period. The egg weight of layers after feeding with FP is shown in Figure 2. The egg weight was only found to be significant different $(\mathrm{P}<0.05)$ after 25 weeks of age. The egg weight of FP6 was significantly higher $(\mathrm{P}<0.05)$ than the FP9 from 26 to 29 weeks of age. However, the egg 


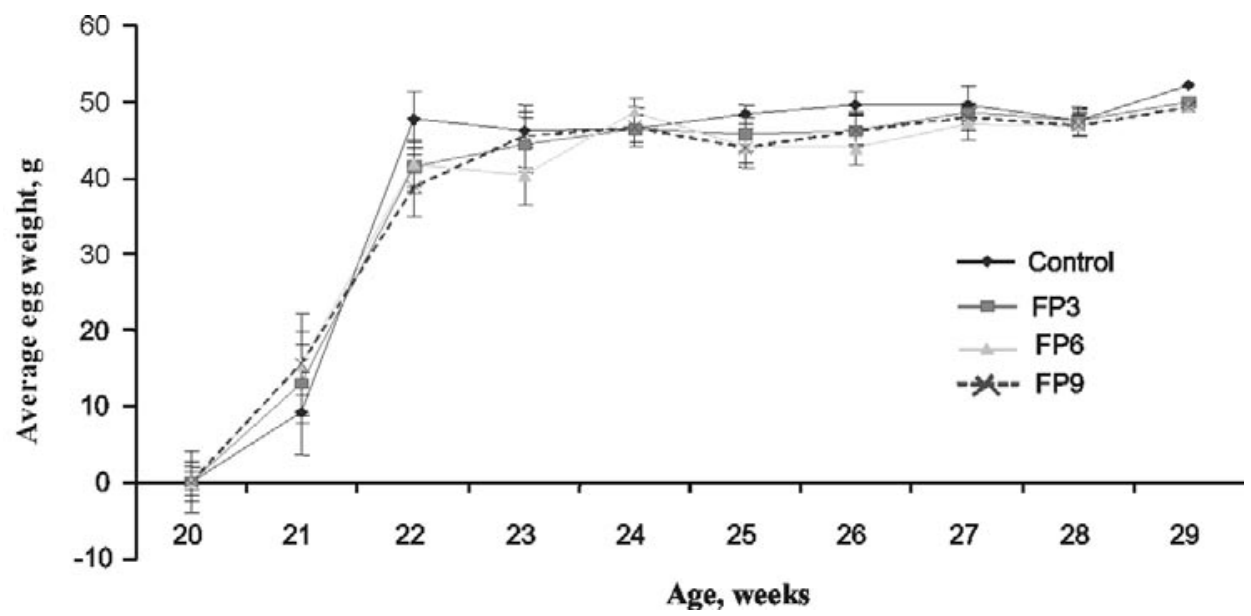

Figure 1. Effects of feeding FP on egg mass of layers, mean $\pm \mathrm{SE}, \mathrm{g}$

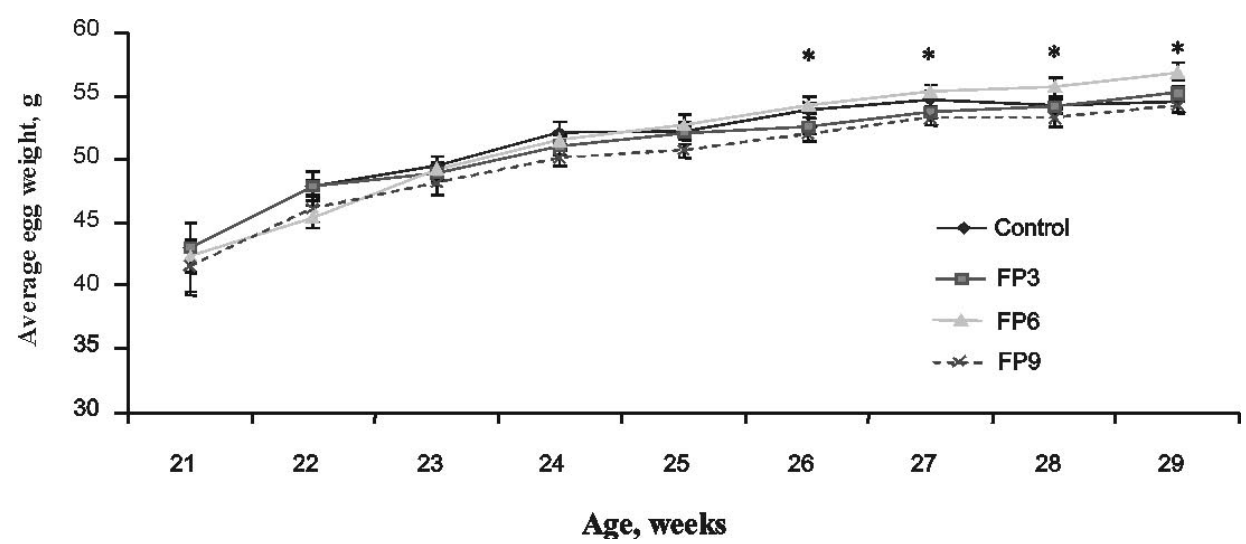

Figure 2. Effects of feeding FP on egg weight of layers, mean $\pm \mathrm{SE}, \mathrm{g}, * \mathrm{P}<0.05$

weights of FP3 and control were found to be significantly lower $(\mathrm{P}<0.05)$ compared to the FP6 at 26 and 29 weeks of age, respectively.

The faecal Enterobacteriaceae counts (Table 4) for all the treatment groups were similar $(\mathrm{P}>0.05)$ at the beginning of the experiment (15 weeks of age). However, the faecal Enterobacteriaceae counts for the FP6 and FP9 groups were significantly lower $(\mathrm{P}<0.05)$ compared to the control groups from 17 weeks of age onwards. Similarly, the FP3-fed group had significantly lower $(\mathrm{P}<0.05)$ faecal Enterobacteriaceae counts as compare with the control group except at 15 and 29 weeks of age. 
Table 4. Effects of feeding fermented product on faecal Enterobacteriaceae counts $\left(\log _{10} \mathrm{cfu} / \mathrm{g}\right)$ in layers

\begin{tabular}{|c|c|c|c|c|c|}
\hline \multirow{2}{*}{$\begin{array}{l}\text { Age, } \\
\text { weeks }\end{array}$} & \multicolumn{4}{|c|}{ Treatments } & \multirow{2}{*}{ Significance } \\
\hline & control & FP3 & FP6 & FP9 & \\
\hline 15 & $7.23 \pm 0.07$ & $7.03 \pm 0.09$ & $6.96 \pm 0.12$ & $6.83 \pm 0.06$ & ns \\
\hline 17 & $7.90^{\mathrm{a}} \pm 0.05$ & $6.79^{b} \pm 0.09$ & $7.45^{b} \pm 0.08$ & $7.38^{b} \pm 0.12$ & * \\
\hline 19 & $6.35^{\mathrm{a}} \pm 0.09$ & $6.11^{b} \pm 0.06$ & $6.55^{\mathrm{b}} \pm 0.14$ & $6.03^{b} \pm 0.12$ & * \\
\hline 21 & $6.83^{\mathrm{a}} \pm 0.09$ & $5.81^{\mathrm{b}} \pm 0.07$ & $5.52^{\mathrm{c}} \pm 0.07$ & $4.85^{\mathrm{d}} \pm 0.05$ & * \\
\hline 23 & $6.25^{\mathrm{a}} \pm 0.03$ & $5.72^{b} \pm 0.11$ & $5.56^{b} \pm 0.07$ & $4.96^{c} \pm 0.11$ & $*$ \\
\hline 25 & $6.49^{\mathrm{a}} \pm 0.09$ & $5.89^{b} \pm 0.12$ & $5.34^{c} \pm 0.12$ & $4.62^{\mathrm{d}} \pm 0.08$ & $*$ \\
\hline 27 & $6.32^{\mathrm{a}} \pm 0.09$ & $5.75^{\mathrm{b}} \pm 0.09$ & $5.00^{c} \pm 0.07$ & $4.64^{\mathrm{d}} \pm 0.09$ & $*$ \\
\hline 29 & $5.92^{\mathrm{a}} \pm 0.09$ & $5.69^{\mathrm{a}} \pm 0.13$ & $5.24^{b} \pm 0.08$ & $4.64^{c} \pm 0.08$ & $*$ \\
\hline
\end{tabular}

the results are presented as mean values $\pm \mathrm{SE}$

values with different superscripts within rows differ significantly at $\mathrm{P}<0.05$

${ }^{\text {ns }}$ no significant difference

* $\mathrm{P}<0.05$

The faecal LAB counts (Table 5) for all the treatment groups were similar $(\mathrm{P}>0.05)$ at the beginning of the experiment (15 weeks of age). The faecal LAB counts for the control and FP3 fed groups were not significantly different $(\mathrm{P}>0.05)$ at 17, 21, 25, 27 and 29 weeks of age. However, the faecal LAB counts for the FP6 and FP9 fed groups were significantly $(\mathrm{P}<0.05)$ higher than the control group.

Table 5. Effects of feeding fermented product on faecal LAB counts $\left(\log _{10} \mathrm{cfu} / \mathrm{g}\right)$ in layers

\begin{tabular}{lccccc}
\hline \multirow{2}{*}{$\begin{array}{l}\text { Age, } \\
\text { weeks }\end{array}$} & \multicolumn{4}{c}{ Treatments } & \multirow{2}{*}{ Significance } \\
\cline { 2 - 5 } & control & FP3 & FP6 & FP9 & \\
\hline 15 & $6.16 \pm 0.11$ & $6.06 \pm 0.11$ & $6.25 \pm 0.04$ & $6.06 \pm 0.10$ & $\mathrm{~ns}$ \\
17 & $6.20^{\mathrm{a}} \pm 0.06$ & $6.24^{\mathrm{a}} \pm 0.02$ & $6.31^{\mathrm{b}} \pm 0.07$ & $6.60^{\mathrm{c}} \pm 0.07$ & $*$ \\
19 & $6.50^{\mathrm{a}} \pm 0.05$ & $6.74^{\mathrm{b}} \pm 0.08$ & $6.73^{\mathrm{b}} \pm 0.03$ & $7.05^{\mathrm{c}} \pm 0.07$ & $*$ \\
21 & $5.91^{\mathrm{a}} \pm 0.10$ & $6.17^{\mathrm{b}} \pm 0.09$ & $6.42^{\mathrm{c}} \pm 0.07$ & $6.56^{\mathrm{c}} \pm 0.07$ & $*$ \\
23 & $5.90^{\mathrm{a}} \pm 0.09$ & $6.13^{\mathrm{b}} \pm 0.06$ & $6.44^{\mathrm{c}} \pm 0.05$ & $6.71^{\mathrm{d}} \pm 0.09$ & $*$ \\
25 & $5.73^{\mathrm{a}} \pm 0.09$ & $5.75^{\mathrm{a}} \pm 0.08$ & $6.28^{\mathrm{b}} \pm 0.05$ & $6.53^{\mathrm{c}} \pm 0.08$ & $*$ \\
27 & $5.98^{\mathrm{a}} \pm 0.06$ & $6.05^{\mathrm{a}} \pm 0.06$ & $6.48^{\mathrm{b}} \pm 0.08$ & $6.65^{\mathrm{b}} \pm 0.09$ & $*$ \\
29 & $5.78^{\mathrm{a}} \pm 0.08$ & $5.98^{\mathrm{a}} \pm 0.11$ & $6.31^{\mathrm{b}} \pm 0.07$ & $6.60^{\mathrm{c}} \pm 0.10$ & $*$ \\
\hline
\end{tabular}

the results are presented as mean values $\pm \mathrm{SE}$

values with different superscripts within a row differ significantly at $\mathrm{P}<0.05$

${ }^{\text {ns }}$ no significant difference

* $\mathrm{P}<0.05$

The faecal $\mathrm{pH}$ (Table 6) of birds at 15 weeks of age for all the experimental groups was not significant different $(\mathrm{P}>0.05)$. There was a trend faecal $\mathrm{pH}$ was lower in those birds fed with FP than the control. Significant difference $(\mathrm{P}<0.05)$ was observed in the faecal $\mathrm{pH}$ between FP9 and control groups after 15 weeks of age. Apparently, the faecal $\mathrm{pH}$ of the FP9 group remained the lowest $(\mathrm{P}<0.05)$ throughout the experimental period. 
Table 6. Effects of feeding fermented product on faecal $\mathrm{pH}$ in layers

\begin{tabular}{|c|c|c|c|c|c|}
\hline \multirow{2}{*}{$\begin{array}{l}\text { Age, } \\
\text { weeks }\end{array}$} & \multicolumn{4}{|c|}{ Treatments } & \multirow{2}{*}{ Significance } \\
\hline & control & FP3 & FP6 & FP9 & \\
\hline 15 & $6.73 \pm 0.07$ & $6.85 \pm 0.05$ & $6.71 \pm 0.02$ & $6.73 \pm 0.02$ & Ns \\
\hline 17 & $6.81^{\mathrm{ab}} \pm 0.03$ & $6.85^{\mathrm{a}} \pm 0.05$ & $6.71^{b} \pm 0.04$ & $6.55^{\mathrm{c}} \pm 0.04$ & $*$ \\
\hline 19 & $6.90^{\mathrm{a}} \pm 0.06$ & $6.79^{\mathrm{ab}} \pm 0.09$ & $6.70^{\mathrm{ab}} \pm 0.07$ & $6.68^{b} \pm 0.04$ & * \\
\hline 21 & $7.00^{\mathrm{a}} \pm 0.05$ & $7.03^{\mathrm{a}} \pm 0.09$ & $6.85^{\mathrm{ab}} \pm 0.06$ & $6.72^{b} \pm 0.06$ & $*$ \\
\hline 23 & $7.57^{\mathrm{a}} \pm 0.05$ & $7.52^{\mathrm{a}} \pm 0.15$ & $7.40^{\mathrm{ab}} \pm 0.08$ & $7.19^{b} \pm 0.03$ & $*$ \\
\hline 25 & $7.09^{a} \pm 0.06$ & $6.99^{\mathrm{a}} \pm 0.06$ & $6.92^{\mathrm{a}} \pm 0.05$ & $6.65^{\mathrm{b}} \pm 0.11$ & $*$ \\
\hline 27 & $7.17^{\mathrm{a}} \pm 0.07$ & $6.85^{b} \pm 0.08$ & $6.95^{b} \pm 0.08$ & $6.89^{b} \pm 0.06$ & $*$ \\
\hline 29 & $7.06^{\mathrm{a}} \pm 0.04$ & $6.86^{\mathrm{a}} \pm 0.07$ & $6.88^{a} \pm 0.05$ & $6.59^{b} \pm 0.12$ & $*$ \\
\hline
\end{tabular}

the results are presented as mean values $\pm \mathrm{SE}$

values with different superscripts within rows differ significantly at $\mathrm{P}<0.05$

ns no significant difference

* $\mathrm{P}<0.05$

\section{DISCUSSION}

Supplementation of FP at 3, 6 and 9\% in layer diet had no effect on body weights, fed intake egg production, FCR and egg mass. There was no mortality recorded during the experimental period. However, feeding higher levels of FP, i.e. 9\% decreased the egg weight compared to control. Reduction in egg weight could be associated with dietary unsaturated fatty acids due to the present of fish in the FP (Law et al., 2007). Gonzalez-Esquerra and Leeson(2000) reported that consumption of unsaturated fatty acids causes a decrease in circulating triacylglycerols of birds and then limit the availability of lipid for yolk formation.

The FP used in this study was rich in $\mathrm{LAB}$, a low $\mathrm{pH}$ and high concentration of lactic acid (Loh et al., 2003b). It has been shown that LAB has antagonistic effect on harmful bacteria either in vitro or in vivo studies (Lindgren and Dobrogosz, 1990; Forestier et al., 2001; Foo et al., 2003). Oral administration of FP (6 and $9 \%$ ) rich in these beneficial bacteria has been shown to be able to reduce the faecal Enterobacteriaceae count. This was attributed to the reduction in faecal $\mathrm{pH}$ as a result of FP supplementation and increased proliferation of the faecal LAB in the present study. The faecal Enterobacteriaceae populations reflected the Enterobacteriaceae-LAB balance in the gastro-intestinal tract (GIT) of the host animal. Several in vivo studies reported that the numbers of Enterobacteriaceae in the GIT of the fermented feed fed groups were lower compared to the control group (van Winsen et al., 2001, 2002; Canibe and Jensen, 2003; Højberg et al., 2003; Loh et al., 2003a,b). This could be due to the fact that intestinal LAB are able to produce antimicrobial compounds such as bacteriocin and organic acids, which are bacteriostatic against pathogenic bacteria (Adam and Nicolaides, 1997; Holzapfel, 2002). The undissociated organic acids decrease the $\mathrm{pH}$ when it passes through 
the cell wall of the bacteria (Immerseel et al., 2003). In the internal environment of the bacteria cell, the molecules will be dissociated and decreased the internal $\mathrm{pH}$. This in turn stops the enzymatic processes and collapses the proton motive force. Growth is inhibited because the cell must spend more energy to maintain internal $\mathrm{pH}$ and this energy cannot be used for other metabolic processes. This probably resulted in less numbers of Enterobacteriaceae that could pass the crop and gizzard, which would reduce the probability of Enterobacteriaceae reaching the caeca and be excreted through the faeces (Heres et al., 2003a,b).

Laying hens fed diets supplemented with FP (6 and 9\%) had higher faecal LAB counts as compare with the control group. However, 3\% FP did not have any effect on faecal LAB count. These results indicate that the LAB count could be elevated as the inclusion level of FP more than $6 \%$. The acidifying effect of the FP on the GIT provided a suitable environment for the growth of LAB (Loh et al., 2003a,b) as reflected in the LAB population in the faeces. The LAB competes against enteropathogens for nutrient, binding and receptor sites (Gallaher et al., 1996; Fujiwara et al., 1997; Kailasapathy and Chin, 2000). They have strong inhibitory effect in preventing the adherence, establishment and replication of pathogenic bacteria (Jin et al., 1998). The LAB are important components for a balanced microflora in the gastrointestinal tract.

Reduction of faecal $\mathrm{pH}$ was observed in layers fed with FP9. This further confirm earlier reports by Heres et al. (2003a,b, 2004) and Loh et al. (2003a,b). Feeding of acidified feed reduce the crop $\mathrm{pH}$ to $\mathrm{pH} 4.5$ (Cox et al., 1972) and therefore lower the $\mathrm{pH}$ in GIT, resulting in a lower faecal $\mathrm{pH}$. A number of factors may account for the beneficial effect of FP and these may act independently or synergistically. It was suggested that the FP reduced $\mathrm{pH}$ in the GIT thereby probably enhanced the activity of volatile fatty acids.

\section{CONCLUSIONS}

In conclusion, the results of feed intake, egg production, feed conversion ratio and egg mass were not affected by the level of fermented product (FP) added in the diet. However, the addition of 6 and 9\% FP diets reduced the Enterobacteriaceae population in faeces and increased the faecal LAB population. Feeding of FP was able to reduce the level of faecal $\mathrm{pH}$. Considering the results of egg weight, faecal microflora counts and $\mathrm{pH}$, addition of $\mathrm{FP}$ up to $6 \%$ in the diet contributed better effects as compare with the rest of treatment groups. These results indicate that FP has the potential to be added in layers feed to promote better health performance without adversely affecting production parameters. 


\section{REFERENCES}

Adams M.R., Nicolaides L., 1997. Review of the sensitivity of different foodborne pathogens to fermentation. Food Control 8, 227-239

Canibe N., Jensen B.B., 2003. Fermented and non-fermented liquid feed to growing pigs: Effect on aspects of gastrointestinal ecology and growth performance. J. Anim. Sci. 81, 2019-2031

Cox N.A., Davis B.H., Watts A.B., Colmer A.R., 1972. Salmonella in the laying hen. 2. The effect of simulated digestive tract $\mathrm{pH}$ levels on the survival of the three species of Salmonella. Poultry Sci. 51, 1268-1270

Demecková V., Kelly D., Coutts A.G.P., Brooks P.H., Campbell A., 2002. The effect of fermented liquid feeding on the faecal microbiology and colostrum quality of farrowing sows. Int. J. Food Microbiol. 79, 85-97

Foo H.L., Loh T.C., Law F.L., Lim Y.Z., Kufli C.N., Rusul G., 2003. Effects of feeding Lactobacillus plantarum I-UL4 isolated from Malaysian Tempeh on growth performance, faecal flora and lactic acid bacteria and plasma cholesterol concentrations in postweaning rats. Food Sci. Biotechnol. $12,403-408$

Forestier C., de Champs C., Vatoux C., Joly B., 2001. Probiotic activities of Lactobacillus casei rhamnosus: in-vitro adherence to intestinal cells and antimicrobial properties. Res. Microbiol. $152,167-173$

Fujiwara S., Hashiba H., Hirota T., Forstner J.F., 1997. Proteinaceous factors in culture supernatant fluids of Bifidobacteria which prevents the binding of enterotoxigenic Escherichia coli to gang liotetraosylceramide. Appl. Environ. Microbiol. 63, 506-512

Gallaher D.D., Stallings W.H., Blessing L.L., Busta F.F., Brady L.J., 1996. Probiotics, caecal microflora and aberrant crypts in the rat colon. J. Nutr. 126, 1362-1371

Gonzalez-Esquerra R., Leeson S., 2000. Effects of feeding hens regular or deodorized menhaden oil on production parameters, yolk fatty acid profile, and sensory quality of eggs. Poultry Sci. 79, $1597-1602$

Heres L., Engel B., Urlings H.A.P., Wagenaar J.A., van Knapen F., 2004. Effect of acidified feed on susceptibility of broiler chickens to intestinal infection by Campylobacter and Salmonella. Vet. Microbiol. 99, 259-267

Heres L., Engel B., van Knapen F., Wagenaar J.A., Urlings B.A.P., 2003a. Fermented liquid feed reduces susceptibility of broilers for Salmonella enteritidis. Poultry Sci. 82, 603-611

Heres L., Engel B., van Knapen F., Wagenaar J.A., Urlings B.A.P., 2003b. Effect of fermented feed on the susceptibility for Campylobacter jejuni colonization in broiler chickens with and without concurrent inoculation of Salmonella enteritidis. Int. J. Food Mcrobiol. 87, 75-86

Holzapfel W.H., 2002. Appropriate starter culture technologies for small-scale fermentation in developing countries. Int. J. Food Microbiol. 75, 197-212

Højberg O., Canibe N., Knudsen B., Jensen B.B., 2003. Potential rates of fermentation in digesta from the gastrointestinal tract of pigs: effects of feeding fermented liquid feed. Appl. Environ. Microbiol. 69, 408-418

Immerseel F.V., Buck J.D., Pasmans F., Velge P., Bottreau E., Fievez V., Haesebrouck F., Ducatelle D., 2003. Invasion of Salmonella enteritidis in avian intestinal epithelial cells in vitro is influenced by short-chain fatty acids. Int. J. Food Microbiol. 85, 237-248

Jin L.Z., Ho Y.W., Abdullah N., Ali M.A., Jalaludin S., 1998. Effects of adherent Lactobacillus cultures on growth, weight of organs and intestinal microflora and volatile fatty acids in broilers. Anim. Feed Sci. Tech. 70, 197-209

Kailasapathy K., Chin J., 2000. Survival and therapeutic potential of probiotic organisms with reference to Lactobacillus acidophilus and Bifidobacterium spp. Immunol. Cell Biol. 78, 80-88 
Law F.L., Loh T.C., Foo H.L., Goh Y.M., Zulkifli I., 2007. Study of lactic acid bacteria and Enterobacteriaceae counts and fatty acid compositions in fermented product. J. Vet. Malaysia (in press)

Lindgren S.E., Dobrogosz W.J., 1990. Antagonistic activities of lactic acid bacteria in food and feed fermentations. FEMS Microbiol. Rev. 87, 149-164

Loh T.C., Foo H.L., Lee K.L., Lim Y.Z., Kufli C.N., 2003a. Effects of fermented fruits on the growth performance, shedding of Enterobacteriaceae and Lactobacilli in post-weaning pigs. AsianAustr. J. Anim. Sci. 16, 1656-1660

Loh T.C., Foo H.L., Tan S.H., Goh Y.M., Shukriyah M.H., Kufli C.N., 2003b. Effects of fermented products on performance, faecal $\mathrm{pH}$, enterobacteriaceae and lactic acid bacteria counts and interrelationships and plasma cholesterol concentration in rats. J. Anim. Feed Sci. 12, 633-644

Mikkelsen L.L., Jensen B.B., 2000. Effects of fermented liquid feed on the activity and composition of the microbiodata in the gut of pigs. Pig News Inform. 21, 59N-66N

SAS, 1991. SAS Institute Inc. Cary, NC

van Winsen R.L, Urlings B.A.P., Keuzenkamp D., 2002. Effect of fermented feed on shedding of Enterobacteriaceae by fattening pigs. Vet. Microbiol. 87, 267-276

van Winsen R.L., Urling B.A.P., Lipman L.J.A., Snijders J.M.A., Keuzenkamp D., Verheijden J.H.M., van Knapen F., 2001. Effect of fermented feed on the microbial population of the gastrointestinal tracts of pigs. Appl. Environ. Microbiol. 67, 3071-3076 